\title{
Desempenho de motor de injeção direta sob misturas de biodiesel metílico de soja
}

\author{
Performance of a direct injection engine using soybeans methyl biodiesel blends
}

\section{Gustavo Heller Nietiedt ${ }^{\mathrm{I} *}$ José Fernando Schlosser $^{\mathrm{I}}$ Rodrigo Lampert Ribas $^{\mathrm{I}}$ Ulisses Giacomini Frantz ${ }^{\mathrm{I}}$ Alexandre Russini ${ }^{\mathrm{I}}$}

RESUMO

\begin{abstract}
O objetivo do trabalho foi avaliar o uso de misturas de biodiesel metílico de soja e diesel em motor de ignição por compressão e injeção direta de combustível. Os ensaios foram realizados em bancada dinamométrica, utilizando as misturas B10, B20 e B100 em comparação ao diesel comercial (B5). O desempenho do motor foi analisado por meio da tomada de potência (TDP) do trator para cada combustivel. Os melhores resultados obtidos para potência e consumo específico de combustivel, respectivamente, foram: B5 $(44,62 \mathrm{~kW} ; 234,87 \mathrm{~g}$ $\left.k W^{-1} h^{-1}\right)$; B10 $\left(44,73 \mathrm{~kW} ; 233,78 g \mathrm{~kW}^{-1} \mathrm{~h}^{-1}\right) ; B 20(44,40 \mathrm{~kW}$;

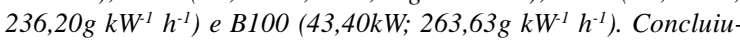
se que os melhores resultados ocorreram sob o uso do combustivel B10 (potência superior em apenas $0,2 \%$ em relação ao combustível B5 e consumo específico inferior em apenas $0,5 \%$ em relação ao B5). O combustivel B100 apresentou diferenças significativas em relação aos demais combustiveis (potência 2,8\% inferior em relação ao B5 e consumo específico 10,9\% maior em relação ao B5).
\end{abstract}

Palavras-chave: bancada dinamométrica, potência, consumo específico.

\section{ABSTRACT}

The aim of this study was to evaluate the use of soybeans methyl biodiesel blends and diesel in an ignition compression engine with fuel direct injection. The tests were performed in a dynamometer bench, using the blends B10, $B 20$ and B100 compared to the commercial diesel (B5). The engine performance was analyzed by tractor power take off (PTO) for each fuel. The best results obtained for the power and the specific fuel consumption, respectively, were: B5

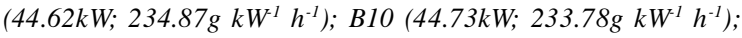
B20 (44.40kW; $\left.236.20 \mathrm{~g} \mathrm{~kW}^{-1} \mathrm{~h}^{-1}\right)$ and B100 (43.40kW; $263.63 \mathrm{~g}$ $\left.k W^{-1} h^{-1}\right)$. It was concluded that the best results happened on the use of B10 fuel (more power in only 0.2\% than fuel B5 and lower specific consumption in only 0.5\% than B5). The B100 fuel showed significant differences compared to the other fuels (power lower $2.8 \%$ than B5 and more specific consumption in $10.9 \%$ than $B 5)$.

Key words: dynamometer bench, power, specific consumption.

\section{INTRODUÇÃO}

O óleo diesel combustível é utilizado em grande escala no país e no mundo, sendo que a maioria das máquinas agrícolas atualmente em operação utiliza este combustível (MIALHE, 1996). Autilização de óleos vegetais em motores de ciclo diesel foi inicialmente considerada pelo seu próprio inventor, mas a crescente oferta de derivados do petróleo durante a primeira metade do século XX criou uma situação bastante favorável à utilização do óleo diesel (SANTOS \& AZEVEDO, 2008). Por outro lado, a crescente conscientização ambiental e a possibilidade de escassez de combustíveis fósseis acarretam em maior demanda por recursos energéticos renováveis, fator que vem sendo determinante para a utilização de plantas oleaginosas, visando à obtenção de biodiesel.

Devido à grande diversidade climática e edáfica, o Brasil apresenta suntuosa capacidade produtiva de diferentes espécies vegetais, o que pode se traduzir em expressivo aumento dos parâmetros de produção do biodiesel. Todavia, qualquer que seja a

'Departamento de Engenharia Rural, Universidade Federal de Santa Maria (UFSM), 97010-493, Santa Maria, RS, Brasil. E-mail: gustavoheller@hotmail.com. *Autor para correspondência. 
matéria-prima utilizada, deve-se estudar as características físico-químicas dos combustíveis gerados, bem como seu efeito no desempenho mecânico do motor. Dentre as vantagens do biodiesel, cita-se a semelhança das suas propriedades às do diesel de origem mineral, que possibilita a utilização sem maiores alterações em motores de ciclo Diesel, acarretando também a redução na emissão de grande parte dos poluentes gerados (SANTOS \& AZEVEDO, 2008).

Em estudos com doze combustíveis alternativos produzidos pela mistura de óleos vegetais com óleo diesel em motor de ciclo Diesel, ALI et al. (1996), em bancada dinamométrica, mostraram que o desempenho do motor foi similar ao obtido com óleo diesel e que não haveria efeito nos parâmetros de desempenho após 200 horas do funcionamento no dinamômetro. CASTELLANELLI et al. (2008) relatam que, na condução de trabalhos com misturas de biodiesel etílico de soja em motor de injeção direta, as misturas de biodiesel B2, B5 e B10 apresentaram desempenho semelhante ao do diesel, sendo que o biodiesel B20 apresentou desempenho superior ao do diesel. Para as outras misturas, houve queda gradual de desempenho à medida que se aumentou a percentagem de biodiesel da mistura, sendo que o puro (B100) apresentou o pior desempenho.

Torna-se importante a condução de trabalhos nesta linha de pesquisa, visto que tais contribuições poderão embasar a utilização de adequadas proporções desses biocombustíveis, puros ou em misturas binárias com óleo diesel, de acordo com a viabilidade técnica e econômica relativa à produção a partir das diferentes matérias-primas utilizadas na obtenção do biodiesel. Assim, o objetivo deste trabalho foi avaliar, em bancada dinamométrica, o desempenho de um motor de ciclo Diesel com diferentes misturas de biodiesel metílico de soja e diesel.

\section{MATERIAL E MÉTODOS}

Os ensaios foram conduzidos no Laboratório de Agrotecnologia, parte integrante do Núcleo de Ensaios de Máquinas Agrícolas da Universidade Federal de Santa Maria. Esse laboratório dispõe de um dinamômetro elétrico, de correntes parasitas, MWD NL 480 com capacidade de frenagem de até $500,0 \mathrm{~kW}$, além de um sistema de controle das cargas aplicadas, um computador contendo um software de aquisição automática de dados, um fluxômetro Oval MIII LSF 41, interligado a uma central de aquisição de dados, para a verificação do volume de combustível consumido (e que serve para o posterior cálculo do consumo específico de combustível) e um conjunto de sensores para o monitoramento de parâmetros como pressão do óleo do motor e condições atmosféricas em tempo real.

As misturas B10, B20 e B100 de éster metílico de soja foram avaliadas em comparação com o diesel comercial, o qual atualmente consiste em uma mistura contendo 5\% de biodiesel adicionado ao diesel de origem mineral (B5). Esses quatro combustíveis foram estudados em um motor de ciclo Diesel Perkins 4000, injeção direta, com 3.000 horas de trabalho, o qual desempenhava uma potência nominal de $45,0 \mathrm{~kW}$ a 1.900 rotações por minuto $(\mathrm{rpm})$. O biodiesel utilizado foi fornecido pela empresa BS BIOS Indústria e Comércio de Biodiesel Sul Brasil S/A, a qual apresentou um laudo do combustível produzido. O resultado da análise dos parâmetros físicos e químicos dessas amostras está em acordo com a Resolução n.7 da ANP (2009) (Tabela 1). Já o óleo diesel utilizado foi adquirido em um posto local de abastecimento.

O delineamento experimental foi o inteiramente casualizado, sob condições de temperatura e umidade relativa do ar constantes, utilizando-se três repetições para cada combustível avaliado. Devido ao fato de o experimento ser conduzido em condições de laboratório e também pela dificuldade de obtenção de maiores volumes deste biocombustível para a realização de ensaios, optou-se pela condução dos experimentos com menor número de repetições.

Para o cálculo do consumo específico de combustível fez-se necessária a determinação da densidade inerente a cada um dos combustíveis utilizados. O procedimento de obtenção dos valores de densidade consistiu na média de três pesagens, em balança de precisão, de um volume de 1,0L de cada combustível. As misturas eram adequadamente homogeneizadas em recipientes com capacidade máxima de sete litros. As proporções foram medidas com o auxílio de duas provetas graduadas com capacidade de $200 \mathrm{ml}$ cada e um copo graduado com capacidade para um litro. Também foi contabilizada a proporção inicial contida no diesel comercial, que era de 5\% de biodiesel, durante a realização do restante das misturas.

A metodologia de aquisição de dados utilizada na realização dos ensaios consiste em um procedimento contínuo em que o acelerador manual do trator é posicionado na posição que fornece a máxima rotação do motor. Em seguida, eram aplicadas cargas crescentes, as quais acarretavam em uma frenagem da TDP, ponto responsável pela transmissão direta do torque, da rotação e da potência gerados pelo motor do trator. Tais cargas acarretam em uma queda constante da rotação, fornecendo os dados que irão 
Tabela 1 - Características físico-químicas do biodiesel metílico de soja utilizado.

\begin{tabular}{lllll}
\hline Item analítico & Unidade & Resultado & Especificação & Métodos (Normas) \\
\hline Massa Específica a $20^{\circ} \mathrm{C}$ & $\mathrm{kg} \mathrm{m}^{-3}$ & 881,3 & $850-900$ & ASTM D 4052 \\
Viscosidade Cinemática a $40^{\circ} \mathrm{C}$ & $\mathrm{mm}^{2} \mathrm{~s}^{-1}$ & 4,083 & $3,0-6,0$ & ASTM D 445 \\
Número de Cetano & - & 44,0 & - & - \\
Teor de Água & $\mathrm{mg} \mathrm{kg}^{-1}$ & 96,4 & Máximo 500 & ASTM D 6304 \\
ContaminaçãoTotal & $\mathrm{mg} \mathrm{kg}^{-1}$ & 1,37 & Máximo 24 & EN 12662 \\
Ponto de Fulgor & ${ }^{\circ} \mathrm{C}$ & 128 & Mínimo 100,0 & ASTM D 93 \\
Teor de Éster & $\%$ massa & 97,2 & Mínimo 96,5 & EN 14103 \\
Enxofre Total & $\mathrm{mg} \mathrm{kg}^{-1}$ & Máximo 50 & ASTM D 5453 \\
Sódio + Potássio & $\mathrm{mg} \mathrm{kg}^{-1}$ & Máximo 5 & EN 14538 \\
Cálcio + Magnésio & $\mathrm{mg} \mathrm{kg}^{-1}$ & 0,407 & Máximo 5 & EN 14538 \\
Índice de Acidez & $\mathrm{mg} \mathrm{KOH} \mathrm{g}^{-1}$ & 0,011 & Máximo 0,50 & ASTM D 664 \\
Glicerina Total & $\%$ massa & 0,354 & Máximo 0,25 & ASTM D 6584 \\
Metanol & $\%$ massa & $<0,208$ & Máximo 0,20 & EN 14110 \\
\hline
\end{tabular}

compor as chamadas curvas de desempenho do motor. Os ensaios eram compostos por três repetições, com duração aproximada de dez minutos cada, para cada um dos combustíveis mencionados. Durante os procedimentos de troca de tratamentos para a continuidade dos ensaios, o motor funcionava por um período não inferior a 30 minutos, para que fosse possível se realizar a queima de resíduos da mistura anteriormente ensaiada, colaborando também para a manutenção da faixa de temperatura de funcionamento do motor. Os procedimentos de ensaio e cálculo dos parâmetros de desempenho seguiram as instruções contidas na norma ABNT NBR 5484 (1985).

Cada variável estudada foi processada em planilhas de cálculo e analisada pelo programa estatístico Software Científico SOC - NTIA/Embrapa, no qual se procedeu inicialmente com a análise da variância (ANOVA), sendo que as médias dos tratamentos foram analisadas pelo teste Tukey com $5 \%$ de probabilidade de erro.

\section{RESULTADOS E DISCUSSÃO}

Os maiores valores de potência na faixa de rotação nominal $(1.900 \mathrm{rpm})$ foram obtidos sob o uso do combustível B10, no entanto, sem apresentar diferenças significativas em relação ao combustível B5 (valores superiores em $0,2 \%$ para o combustível B10). As reduções nos valores de potência sob maiores proporções de biodiesel adicionado ao diesel comercial podem ser atribuídas ao menor poder calorífico do biodiesel (Tabela 2). CASTELLANELLI et al. (2008) explicam que, se a diferença nos valores de torque, potência e consumo específico se mantém ao longo das curvas, pode-se justificá-la devido à inferioridade do biodiesel em relação ao diesel na propriedade poder calorífico. Entretanto, quando se percebe maior distanciamento entre as curvas a partir de certas faixas de rotação, deduz-se que há também atomização ineficiente do combustível, devido à maior viscosidade atribuída a maiores teores de biodiesel na mistura. Essa atomização deficiente acarreta prejuízos inerentes à queima do combustível. A proporção B100 apresentou diferenças estatisticamente significativas em relação ao combustível B5, com valores de potência inferiores em 2,8\% (Tabela 2). Esses valores são ligeiramente superiores às reduções obtidas por CORRÊA et al. (2008) para a potência no motor com os diferentes combustíveis, sendo que as diferenças percentuais foram, no máximo, de 2,2\%.

SegundoEJIM (2007), misturas binárias com maiores proporções de biodiesel ainda podem proporcionar características de atomização adequadas

Tabela 2 - Desempenho do motor quanto à potência e o consumo específico sob os diferentes combustíveis avaliados.

\begin{tabular}{llc}
\hline Combustível & $\begin{array}{c}\text { Potência } \\
(\mathrm{kW})^{1}\end{array}$ & $\begin{array}{c}\text { Consumo específico } \\
\left(\mathrm{g} \mathrm{kW}^{-1} \mathrm{~h}^{-1}\right)\end{array}$ \\
\hline B10 & $44,73 \mathrm{a}^{*}$ & $233,78 \mathrm{~b}^{*}$ \\
B5 & $44,62 \mathrm{a}$ & $234,87 \mathrm{~b}$ \\
B20 & $44,40 \mathrm{~b}$ & $236,20 \mathrm{~b}$ \\
B100 & $43,40 \mathrm{c}$ & $263,63 \mathrm{a}$ \\
Média & 44,28 & 242,12 \\
C.V $(\%)$ & 0,98 & 5,0 \\
\hline
\end{tabular}

${ }^{1}$ Valores não corrigidos em relação às perdas pelo acoplamento a TDP do trator. Pode-se estimar um aumento de 8 a $10 \%$ nos valores de potência em função das perdas.

*Valores não seguidos pelas mesmas letras diferem entre si pelo Teste de Tukey com 5\% de probabilidade de erro. 
para a formação da mistura em motor diesel. Aliandose tal fator ao aumento dos valores de número de cetano em misturas contendo maiores teores de biodiesel, o que acarreta melhoria da queima do combustível na câmara de combustão, justifica-se o melhor desempenho do combustível B10 em relação ao B5. Já o combustível B20 apresentou valores levemente inferiores aos combustíveis B5 e B10 $(44,4 \mathrm{~kW}$, que representa uma diferença de $0,5 \%$ em relação ao $\mathrm{B} 5$ ) na faixa de potência máxima do motor (1.900rpm) (Figura 1). Todavia, essa diferença foi constatada como estatisticamente significativa. Esses resultados contrastam com os obtidos por CANAKCI (2006) e MURUGESAN (2008), os quais sugerem que misturas de biodiesel e diesel de origem mineral, até um limite de $20 \%$ (B20), ainda podem ser utilizadas sem que sejam realizadas maiores modificações no motor.

Quanto ao consumo específico de combustível, na rotação em que normalmente ocorrem os menores valores (1.500rpm) para o motor ensaiado, o combustível B100 apresentou valores cerca de 10,9\% maiores quando comparado aos valores apresentados pelo combustível B5 (Tabela 2). Os resultados seguem a mesma tendência dos valores obtidos por HILBERT et al. (2002) que citaram um aumento médio de 9,5\% no consumo específico de combustível com o uso de biodiesel, quando comparado ao diesel de petróleo. Esses resultados também se enquadram nas tendências identificadas por MAZIERO et al. (2006) que constataram que, em um motor de $92,0 \mathrm{~kW}$, ocorreu aumento médio do consumo específico em cerca $10 \%$ sob a utilização de biodiesel puro (B100), quando comparado ao diesel de origem mineral devido à redução do rendimento térmico do motor.

O combustível que apresentou os menores valores de consumo específico ao longo de toda a curva foi a proporção de mistura $\mathrm{B} 10$ e, na rotação de menor consumo específico para o motor ensaiado, os valores foram inferiores cerca de $0,5 \%$ em relação ao B5, não caracterizando diferença estatística significativa entre tais combustíveis (Figura 2). O combustível B20 apresentou consumo específico levemente superior ao apresentado pelo combustível B5 $(0,6 \%)$, todavia essa diferença não foi significativa (Tabela 2). Quanto ao consumo horário de combustível, é pertinente salientar que as diferenças para todas as proporções de mistura avaliadas não foram significativas. Tal fato pode ser facilmente explicado, visto que o consumo horário de combustível não leva em consideração a potência produzida $(\mathrm{kW})$ por massa de combustível consumida (grama). Assim, como o biodiesel apresenta maior densidade quando comparado ao óleo diesel convencional, dado volume de óleo diesel possui massa inferior à apresentada pelo mesmo volume de biodiesel, acarretando diminuição da diferença quando se comparam apenas valores de volume de combustível consumido $\left(\mathrm{L} \mathrm{h}^{-1}\right)$.

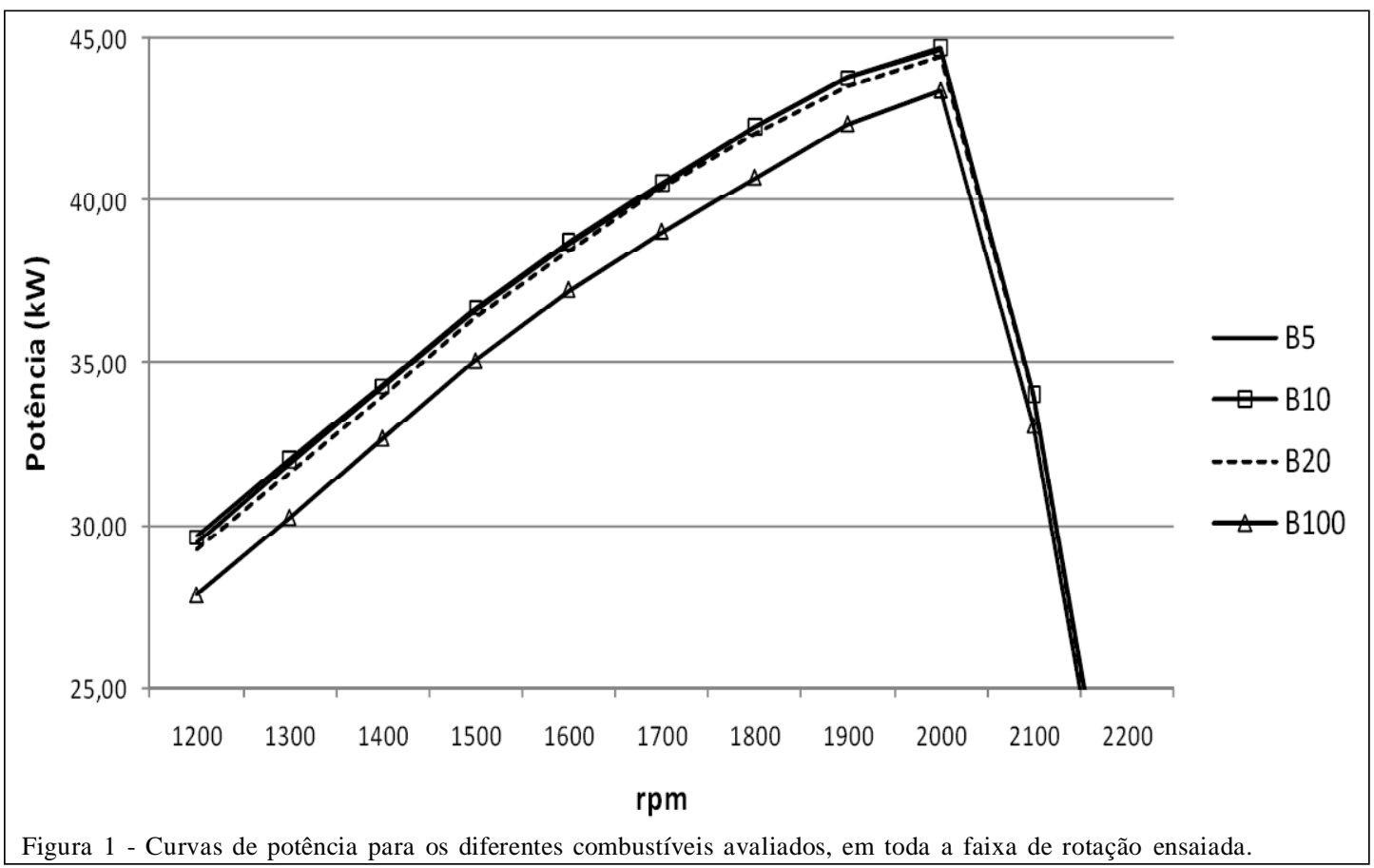

Ciência Rural, v.41, n.7, jul, 2011. 


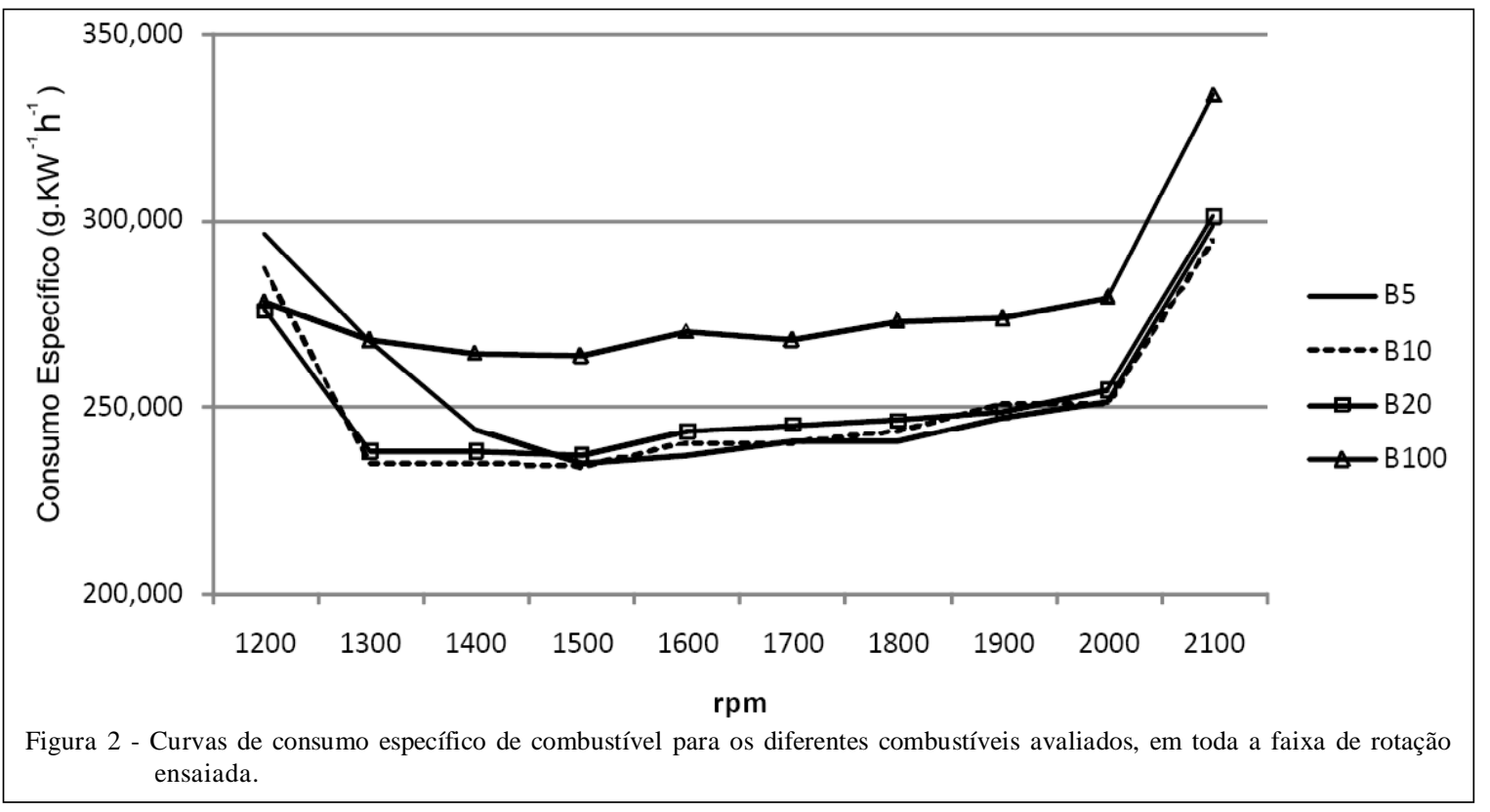

\section{CONCLUSÃO}

Os combustíveis B10 (10\% de biodiesel e $90 \%$ de diesel mineral), B20 (20\% de biodiesel e $80 \%$ de diesel mineral) e B100 (100\% de biodiesel) proporcionam alterações no desempenho do motor em comparação com o combustível B5 (5\% de biodiesel e 95\% de diesel mineral), sendo que o combustível B10 apresenta os melhores resultados, com potência superior em $0,2 \%$ em relação ao combustível B5 e consumo específico inferior em $0,5 \%$. Já o combustível B100 expressa os menores valores de potência, 2,8\% inferiores aos valores de B5, e os maiores valores de consumo específico, 10,9\% maiores em relação ao combustível B5.

\section{REFERÊNCIAS}

ABNT NBR 5484. Motores alternativos de combustão interna de ignição por compressão (Diesel) ou ignição por centelha (Otto) de velocidade angular variável Ensaio. Rio de Janeiro, 1985. 8p.

ALI, Y. et al. Effect of alternative diesel fuels on heat release curves for Cummins N 14410 diesel engine. Transactions of the ASAE, v.39, n.3, p.407-414, 1996. Disponível em: <http:/ /www.biodiesel.org/resources/reportsdatabase/reports/tra/ 19950901_tra-021.pdf>. Acesso em: 14 ago. 2009.

ANP- AGÊNCIA NACIONAL DE PETRÓlEO, GÁS NATURAL E BIOCOMBUSTIVEIS. Relatório anual. 2009. Disponível em: <http://www.anp.gov/?id=324>. Online. Acesso em: 21 jun. 2010.

CANAKCI, M. Performance and exhaust emissions of a biodiesel engine. Applied energy, v.83, p.594-605, 2006.
Disponível em: <http://www.sciencedirect.com/ science?_ob=ArticleURL\&_udi=B6V1T4GTVYX51\&_user=10\&_coverDate=06 $\% 2 \mathrm{~F} 30 \% 2 \mathrm{~F} 2006 \&$ rdoc $=1 \&$ fmt=high\&_orig=gateway\&_origin $=\mathrm{g}$ ateway\&_sort=d\&_docanchor $=\&$ view $=c \&$ _searchStrIl $=1755484110 \&$ reunOrigin= google\&_acct $=C 000050221 \&$ \&version $=1 \&$ _urlVersion $=0 \&$. userid $=10 \& \mathrm{md} 5=2 \mathrm{e} 600 \mathrm{~b} 88 \mathrm{cf} 84 \mathrm{e} 4 \mathrm{~d} 150151 \mathrm{~d} 218 \mathrm{ad} 17 \mathrm{c} 0 \mathrm{a} \&$ searchtype $=\mathrm{a}>$. Acesso em: 15 out. 2009. doi: 10.1016/j.apenergy.2005.05.003.

CASTEllanelli, M. et al. Desempenho de motor ciclo diesel em bancada dinamométrica utilizando misturas diesel/ biodiesel. Revista Engenharia Agrícola, v.28, n.1, p.145153, 2008. Disponível em: <http://www.scielo.br/ scielo.php ? script $=$ sci_arttext \& pid $=$ S 0100 69162008000100015>. Acesso em: 08 fev. 2010. doi: 10.1590/ S0100-69162008000100015.

CORRÊA, I.M. et al. Desempenho de motor diesel com misturas de biodiesel de óleo de girassol. Revista Ciência e Agrotecnologia, v.32, n.3, p.923-928, 2008. Disponível em: $<\mathrm{ht} \mathrm{tp}: / / \mathrm{ww}$ w. proce eding s. s c i e 1 o.b r / scielo.php?pid=MSC0000000022006000100045\&script=sci_arttext $>$. Acesso em: 23 jan. 2010.

EJIM, C.E. Analytical study for atomization of biodiesel and their blends in atypical inyector: surface tension and viscosity effects. Fuel, v.86, p.1534-1544, 2007. Disponível em: <http:/ /www.sciencedirect.com/science?_ob=ArticleURL\&_udi=B6V3B$4 \mathrm{MG} 1 \mathrm{MNX} 3 \&$ \& user $=687358 \&$ coverDate $=08 \% 2 \mathrm{~F} 3$

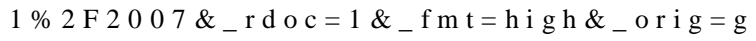
ateway \&_origin $=$ gateway $\& \_s o r t=d \& \_d o c a n c h o r=\& v i e w=c \&$. acct $=$ C000037899\&_version $=1 \& \_u r l$ Version $=0 \& \_u s e r i d=687358 \&>$. Acesso em: 12 jul. 2009. doi:10.1016/j.fuel.2006.11.006.

HILBERT, J.A. et al. Rendimiento comparative de biodiesel y gasoil en tractors agricolas. Buenos Aires: INTA, 2002. 234p.

MAZIERO, J.V.G. et al. Avaliações de emissões poluentes de um motor diesel utilizando biodiesel de girassol como combustível. Revista Engenharia na Agricultura, v.14, 
n.4, p.287-292, 2006. Disponível em: <http:// br.monografias.com/trabalhos-pdf900/biodiesel-girassolcombustivel/biodiesel-girassol-combustivel.pdf >. Acesso em: 13 dez. 2009. doi: 10.1590/S0100-69162009000300008.

MIALHE, L.G. Máquinas agrícolas: ensaios \& utilização. Piracicaba: FEALQ, 1996. 722p.

MURUGESAN, A. Biodiesel as an alternative fuel for diesel engines - a review. Renewable \& Sustentable Energy Reviews, 2008. Disponível em: <http://www.elsevier.com/wps/ find/simple_search.cws_home? boost $=$ true $\&$ needs_keyword $=$ true \& adv $=$ false \& a ction $=$ si mple_search\&default $=$ default $\&$ keywords=murugesan $>$. Acesso em: 07 jul. 2009. doi: 10.1016/j.ibiod.2010.09.00.

SANTOS, M.A.; AZEVEDO, C.J.V. Aspectos técnicos e ambientais relativos ao uso de biodiesel em motores de combustão. Revista de Gestão Integrada em Saúde do Trabalho e Meio Ambiente, v.3, n.1, p.1-18, 2008. Disponível em: <http://www.revistaic.sp.senac.br/index.php/ITF/article/ viewFile/94/119>. Acesso em: 19 mar. 2010 